\title{
escolas, Escolas: \\ a presença da arquitetura nos espaços de formação
}

\author{
Miranda Zamberlan Nedel, \\ Givaldo Luiz Medeiros*
}

\begin{abstract}
Resumo Com o objetivo de analisar o papel da arquitetura à formação, elegeu-se como objeto de estudo o edifício escolar e a relação entre arquitetura e educação no âmbito da produção arquitetônica das denominadas Escola Paulista e Escola do Porto. Amparada por pesquisas bibliográficas e iconográficas, a metodologia abrangeu entrevistas, visitas de campo, fotografias, diagramas e sessões de desenho com alunos, visando a uma ampla tradução da vivência real dos espaços e ao registro vivo dessa apreensão. Desdobra-se através do texto uma dupla acepção da noção de escola, enquanto recinto potencial das práticas pedagógicas e do desenvolvimento social, bem como laboratório privilegiado de ensaio, formulação e consolidação das duas Escolas de arquitetura.
\end{abstract}

Palavras-chave: edifícios escolares, Escola Paulista, Escola do Porto.

\section{escuelas, Escuelas: la presencia de la arquitec- tura en los espacios de formación}

\begin{abstract}
Resumen Para analizar el papel de la arquitectura en la formación, se eligió como objeto de estudio el edificio escolar y la relación entre arquitectura y educación en el ámbito de la producción arquitectónica de las Ilamadas Escola Paulista y Escola do Porto. Apoyada en investigaciones bibliográficas e iconográficas, la metodología abarcó entrevistas, visitas de campo, fotografías, esquemas y sesiones de dibujo con estudiantes, buscando una traducción amplia de la experiencia real de los espacios y el registro vívido de esta aprehensión. A través del texto se despliega un doble sentido de la noción de escuela, como lugar potencial de prácticas pedagógicas y de desarrollo social, así como laboratorio privilegiado para testear, formular y consolidar las dos Escuelas de Arquitectura.
\end{abstract}

Palabras clave: edificios escolares, Escuela Paulista, Escuela de Oporto.

\section{schools, Schools: the presence of architecture in educational spaces}

\begin{abstract}
In order to analyze the role of architecture in formation, the school building and the relationship between architecture and education within the scope of the architectural production of the so-called Escola Paulista and Escola do Porto were chosen as the object of study. The methodology included bibliographic and iconographic research, interviews, site visits, photographs, diagrams, and drawing sessions with students, for a comprehensive translation of the real experience of the spaces and for the living record of this apprehension. A double meaning of the notion of school unfolds through the text, as a potential hall for pedagogical practices and for social development, as well as a privileged laboratory for testing, formulating and consolidating both schools of architecture.
\end{abstract}

Key words: school buildings, Paulista School, Porto School. 
* Miranda Zamberlan Nedel é Arquiteta e Urbanista, Doutoranda do Programa de Pós-Graduação em Arquitetura e Urbanismo do Instituto de Arquitetura e Urbanismo da Universidade de São Paulo, ORCID <https://orcid.org/00000001-8132-3634>. Givaldo Luiz Medeiros é Arquiteto, Professor e pesquisador do Instituto de Arquitetura e Urbanismo da Universidade de São Paulomente ao Instituto de Arquitetura e Urbanismo, ORCID <https://orcid. org/0000-0003-2299-0095>. estes tempos nefastos, quando a arquitetura e a urbanidade se esvaem a reboque da dissolução da res publica no Brasil, rever momentos notáveis no quadro de desenvolvimento do ofício proporciona um contraponto radical a quem possa imaginar - e logo conformar-se - que a lógica do mundo e das coisas circunscreve-se à retrógrada clave atual. O enlace entre a síntese de uma linguagem arquitetônica modelar e a qualificação dos espaços de formação permeia a história do campo disciplinar no Brasil e em Portugal, mormente em duas linhagens que cá e lá constituíram modos de fazer exemplares e galgaram ampla ressonância social ao inscreverem a arquitetura na esfera pública, divisando e disseminando intuitos inclusivos e gregários para a vida comum: a Escola Paulista e a Escola do Porto.

Confrontadas em retrospectiva, permitem desdobrar a dupla acepção do termo "escola", enquanto recinto voltado à educação e postura distintiva alçada a ideal ético e estético, a partir de algumas obras implantadas no estado de São Paulo e na região do Porto, seus desenhos e desígnios, e pelo cotejamento de duas obras seminais, a Faculdade de Arquitetura e Urbanismo da Universidade de São Paulo (FAUUSP) e a Faculdade de Arquitectura da Universidade do Porto (FAUP). Instituições de ensino que se efetivaram socialmente mediante sua arquitetura; Escolas acordes a uma sorte de legado arquitetônico que perpassa gerações, de modo nem sempre deliberado ou univalente, em torno do qual se decantam referências e formas afins de desenho. Dualidade que assume, de partida, um nuance especular: o projeto de arquitetura como âmbito de reflexão, ressonância, manifestação e cogitação das concepções pedagógicas, vivenciais ou sociais; a escola - o edifício escolar - como laboratório privilegiado de ensaio, formulação e consolidação de determinada Escola de arquitetura, expressão dos respectivos modos de saber, fazer e conceber.

Sem refutar a noção estrita de local que faculta a ascensão social, interessa realçar o papel das escolas na conformação da coletividade, em conjunto com o das individualidades, e valorar o princípio essencial de educação dos sujeitos enquanto cidadãos. O pressuposto de que a situação espacial é determinante na constituição dos ambientes de ensino - na formação de uma Paideia - fundamenta a inter-relação entre concepções arquitetônicas e pedagógicas no contexto das Escolas Paulista e do Porto, levando-nos a estimar as escolas como ambientes transdisciplinares, onde os fatores pedagógicos, psicológicos, sensoriais, espaciais e urbanos condicionam e assistem a apreensão da ordem econômica, cultural, social e política.

Intrinsicamente associada à trajetória das referidas Escolas, a arquitetura escolar pública do Brasil e de Portugal agrega variados exemplares em que as concepções espaciais propiciam o convívio social e renovam o imaginário espacial, incidindo, por conseguinte, na amplitude da formação. Enquanto domínio de trocas interpessoais, os estabelecimentos de ensino propiciam ademais o florescer concomitante de posturas arquitetônicas comuns a um arco de agentes, notadamente quando abrigam um curso de graduação em Arquitetura e Urbanismo e institui-se destarte como referência 
1 Atividades realizadas com apoio do Programa Institucional de Bolsas de Iniciação Científica (PIBIC -USP) em 2013-14, da Fundação de Amparo à Pesquisa do Estado de São Paulo (FAPESP) em 201516 (Processo $n^{\circ} 14 / 25317-0$ ) e do Programa de Bolsas de Intercâmbio Internacional para os Alunos de Graduação da USP em 201617 (Programa de Bolsas Mobilidade Internacional Santander). primordial, cristalizando-se em certa medida como uma imago, para a qual volvem tantos desenhos gestados em sucessão, sejam para escolas ou outros fins, em inspirada deferência e descendência.

Tais questões acompanharam os objetos de estudo de três pesquisas ${ }^{1}$, elaboradas em sintonia com o Acordo de Cooperação Internacional de Pesquisa firmado entre a FAUP e o Instituto de Arquitetura e Urbanismo da Universidade de São Paulo (IAUUSP). No decorrer dos trabalhos, adotou-se um enfoque persistente em torno da confluência recíproca dos sentidos atribuídos à [E]escola, apoiado na copiosa, porém inestimável historiografia sobre a arquitetura escolar de cada país, por meio do qual se vislumbraram aspectos relevantes, tratados a seguir, para a compreensão tanto da inter-relação dos aspectos pedagógicos e espaciais quanto das próprias obras arquitetônicas analisadas.

\section{Sobre Escolas}

A abordagem da arquitetura afeita à noção de Escola teve como propósito realçar sua dimensão cultural, em face do pendor eclético que permeia as manifestações contemporâneas, e suplantar a importância atribuída ao papel das individualidades - o star system arquitetural - pela ênfase nas práticas coletivamente assentadas. À revelia da espetacularização cenográfica urbana que embala a disputa entre as cidades globais ou da tendência à dissociação conceitual entre a forma e os elementos tectônicos que há algum tempo permeiam o ensino do ofício mundo afora, a pesquisa buscou realçar posturas nas quais o saber arquitetônico ampara-se em razões técnico-construtivas, ao largo dos impulsos autorais.

Ciente do risco implícito a toda adjetivação localista, consoante a advertência de Julio Katinsky acerca da denominação "arquitetura paulista" como "perigosa montagem ideológica" (1988), ao empregar o termo Escola busca-se não obstante demarcar a conformação cultural de um campo disciplinar, sem qualquer conotação regionalista. O incômodo coetâneo de Rosa Artigas e Dalva Thomaz relativo ao emprego do termo "brutalismo" na recepção da obra de Vilanova Artigas contém, nesse sentido, em germe, a potencialidade de redimensionar o que, à primeira vista, parece impertinente:

A partir de tais perspectivas colocadas pela obra de Artigas, instaura-se um clima de pesquisa e de experimentação entre os arquitetos paulistas que permite o surgimento de uma produção consequente, em termos do desenvolvimento técnico e da vontade estética. [...] Esse impulso criador e, de certa forma, impregnado de sentido crítico, ganhou espaço e estabeleceu-se no plano nacional como uma forma "paulista" de pensar e fazer arquitetura. Talvez essa inquietação, essa vontade enorme de transgredir, que está presente na arquitetura de São Paulo, com Artigas à frente, colocasse um certo desconforto para seus críticos mais frequentes que preferiam, face ao vigor do conforto, chamá-la mesmo de brutalista. (ARTIGAS; THOMAZ, 1988, p. 62-63)

Certamente há conotação ideológica restritiva no rótulo "brutalista" - mais até do que na denominação "arquitetura paulista" -, a justificar a indignação das autoras ante a persistência de tal impropriedade. Contudo, o "impulso criador" e o "sentido crítico" inato a essa produção galgaram repercussão nacional justamente sob o prisma do "desconforto" causado, medida de vigor e radicalidade que emerge como referência ética para os tempos atuais. 
Pautados pelo exemplo radical de duas posturas que ansiaram tornar-se universais, neste artigo sustenta-se que a noção de Escola permite instruir investigações "consequentes", por circunstanciar os objetos de estudo e realçar influências afins ou peculiares. Desse modo, se a arquitetura moderna se impôs como parâmetro universal e se, por outro lado, a arquitetura realizada no Brasil e em Portugal constitui uma só pátria, como quer Alexandre Alves Costa (2017), sondar a constituição de ambas as Escolas possibilita mensurar o que há de comum ou específico em cada vertente e entre nós.

Sobressai na caracterização dessas Escolas o papel seminal de Artigas em São Paulo e de Fernando Távora no Porto. O diálogo tenso com os signos da modernidade; a associação da verdade dos materiais à razão construtiva; o ensejo de uma nova adequação histórica e social da arquitetura, em atuações a um tempo ancoradas no real e voltadas à sua transcendência; a conformação afinal de posições que se irradiam ao redor e além deles no plano local, a incitar os pares em impulso exemplar pela via do projeto, não obstante a tomada de posição política e cultural; a contrapartida da superação dos dilemas vivenciados com "uma atitude crítica em face da realidade" (ARTIGAS, 2004, p.50) ou "com a esperança firme de que [seguir] é a única [posição] possível para aqueles que nasceram para aumentar ao passado algo de presente e algumas possibilidades de futuro, para aqueles para quem viver é criar alguma coisa de novo" (TÁVORA, 1947, p.47). Orientações produtivas da história, de sua transformação, que demarcam o inequívoco caráter nacional de ambas as trajetórias e obras, ao largo de qualquer circunscrição local.

Em Artigas, a preocupação política com a dimensão social da arquitetura materializa-se na plasticidade do concreto aparente, plasmando um renovado sentido de interioridade, em uma síntese que integra obra e sítio através dos volumes em permanente tensão com o solo. "Nesses projetos, o edifício nunca "brota" do solo: pousa e pesa sobre chão" (ZEIN, 1984, p. 86). Obras que efetuam uma dialética de pares opostos, em tensão e equilíbrio, na relação entre forma e estrutura, chão e cobertura, ancoragem no solo e amplitude dos vãos, materialidade dos planos e continuidade espacial.

Entre os arquitetos da chamada Escola Paulista difunde-se então uma arquitetura com clara definição volumétrica, empenhada em desenvolver a tecnologia do concreto armado, deixado à vista, franqueada à cidade e radicada na importância atribuída à estrutura para a definição formal e na reunião do programa em torno de um espaço central, a qual "implica uma utopia de sociedade. [...] O que a caracteriza é essa intenção subjacente e não exatamente as questões construtivas, embora se manifeste pela construção" (ZEIN, 1988, p. 54). "As cidades como as casas; as casas como as cidades", segundo a célebre formulação de Artigas (1969, p.18), a promover uma nova síntese tipológica que renova o sentido público da obra de arquitetura.

De outra parte, Távora fornece as lições que dão tessitura à arquitetura do norte de Portugal:

Nunca se tratou de revogar o Movimento Moderno, tratou-se de manter uma ordem arquitetônica com valor universal que o integrasse e redefinisse permanentemente. Sem produzir novos modelos, cada obra é um percurso de reflexão que do sítio fixa a forma, cada forma. É o seu método, o desenho do seu processo de desenho que ensina mais do que a sua obra. (ALVES COSTA, 1993, p. 19) 
Refutada inicialmente por seus representantes, a expressão Escola do Porto passou a ter mesmo entre eles uso corrente. Sob a égide do enlace entre desenho e projeto, constitui-se uma tradição que remonta à Escola de Belas-Artes, reconhece a cultura construtiva vernacular, valora o organicismo no modernismo, incorpora o espírito do lugar e evidencia a fenomenologia do espaço. Inúmeras argumentações demonstram sua atualidade, como Remo Dorigati (2008) bem expressa:

Vemos este fenómeno sobretudo como uma experiência que partilhou o sonho de resgatar Portugal do seu isolamento e, ao mesmo tempo, não renunciou à própria identidade histórica. [...] Então aparecem arquiteturas que se libertaram das formas históricas mas não do carácter profundo da sua cultura: a forma de dispor os edifícios na paisagem, a sutil manipulação da luz, as escalas discretas e os volumes articulados, uma mistura de materiais antigos e de técnicas contemporâneas. Então a definição de "Escola do Porto" poderá ficar. (DORIGATI, 2008, p. 88)

Em ambas as Escolas verificam-se afinidades, influências, divergências e convergências relativas às experimentações formais, ao conteúdo, simbologias, formas de relacionamento com o entorno, posicionamentos políticos e ideológicos. Apesar da tradição ser transmitida entre as gerações de arquitetos, existe sempre uma nova possibilidade de significação e de tratamento dos problemas arquitetônicos. Dessa forma, se uma herança ou influência é assumida, não é passivamente, mas decorre de uma transformação dinâmica, condicionada pelas modificações do contexto nacional, local, político, econômico, social, cultural e ideológico.

Para adensar a compreensão dos argumentos expostos, a seguir se encadeiam as pesquisas realizadas, não em ordem cronológica, mas das últimas à primeira, de modo a expor os vínculos entre escolas e Escolas, entre a produção de edifícios escolares e a consolidação cultural de dois modos de conceber a arquitetura, a partir de sua própria constituição.

\section{Entre escolas: concepções espaciais e práticas pedagógicas no aparelhamento institucional do ensino público paulista}

As escolas produzidas no estado de São Paulo, para as quais Artigas e centenas de arquitetos, a ele associados ou não, foram incumbidos da concepção arquitetônica, espacial e muitas vezes pedagógica constituem uma notável fonte de estudo para a análise historiográfica da relação entre arquitetura e educação, permitindo verificar o papel da arquitetura escolar para a formação cidadã dos sujeitos que a habitam. Com este objetivo, o estudo abarcou cinco períodos referenciais da produção pública arquitetônica paulista: o Convênio Escolar (1949-59), o Instituto de Previdência do Estado de São Paulo (IPESP, 1959-66), o Fundo Estadual de Construções Escolares (FECE, 1960-76), a Companhia de Construções Escolares do Estado de São Paulo (CONESP, 1976-87) e a Fundação para o Desenvolvimento da Educação (FDE, 1987). Tal estudo constituiu o cerne da pesquisa intitulada "Concepções espaciais e práticas

2 Sobre tal pesquisa, cf. Nedel, Medeiros (2018). pedagógicas: análise de obras arquitetônicas referenciais no ensino público paulista" 2 .

As interpretações consolidadas acerca da arquitetura escolar paulista, cotejadas durante o trabalho, indicam que, embora as concepções pedagógicas nem sempre tenham pautado as concepções espaciais, os princípios arquitetônicos reverberaram, 
com frequência, no campo da educação. A pesquisa reitera o argumento de que o espaço físico não determina, por si só, a orientação do ensino, mas influencia e em certa medida instiga práticas pedagógicas e sociais. A despeito da relativa autonomia do projeto de arquitetura e da prevalecente inexistência de trocas concretas entre pedagogos e arquitetos, observaram-se, ao longo dos cinco períodos estudados, contribuições variadas à dinâmica escolar, embora com frequência entre posturas arquitetônicas que não se propunham a influir nos planos e nas práticas pedagógicas.

Marco inicial dos vínculos apontados, no Convênio Escolar o papel seminal do educador Anísio Teixeira fomenta uma indubitável intervenção dos princípios pedagógicos na arquitetura, por meio do conceito integrado de escola-classe e escola-parque, o qual tem como expressão mais bem-acabada o Centro Educacional Carneiro Ribeiro, em Salvador. Unidades distribuídas sistematicamente em tal período no município de São Paulo, acarretaram, ademais, a valorização dos espaços vocacionados à sociabilização e ao desenvolvimento de atividades extracurriculares para a formação plena das capacidades infantis.

O período que abrange o IPESP (1959-66) e o início do FECE (1960-c.70) constitui outro momento chave na consubstanciação da Escola Paulista e da arquitetura brasileira, ao configurarem nova etapa de síntese, possível dada a intensa e diversa produção precedente, a qual possibilitou uma revisão dos posicionamentos vigentes, em alinhamento às discussões sociais e políticas contemporâneas. Nesse quadro, as escolas de Vilanova Artigas formam um conjunto modelar, com ampla receptividade, em que o pátio central constitui o polo nuclear da comunidade escolar, o espaço de encontro e de manifestação pública, marcado igualmente pela franca permeabilidade entre interior e exterior, materializando espacialmente os anseios sociais e democráticos do arquiteto.

Na fase final do FECE (c.1970-76) e no período da CONESP (1976-87), a padronização dos elementos construtivos acentua-se, em decorrência de imperativos de custos e prazos, ao passo que o caráter laboratorial e de profícua experimentação arquitetônica nas construções escolares - não restrito ao projeto espacial de programas específicos, visto que expressão das intenções políticas e sociais dos arquitetos - reduz-se ao atendimento de demandas e objetivos mais ou menos determinados.

A FDE (1987-) continua e aprofunda a sistematização dos instrumentos de produção e de gestão da rede física escolar. Entretanto, o ano de 2003 demarca uma inflexão no processo, devido à inclusão de novos espaços no programa escolar, como a quadra coberta, que permite a abertura da escola à comunidade, e a sala de informática, mas sobretudo em decorrência da adoção da pré-fabricação dos elementos construtivos.

Do Convênio Escolar à FDE, tal trajetória confunde-se com a própria consolidação da arquitetura moderna no estado de São Paulo, em contraponto a outras vertentes notáveis por realizar obras de exceção, então dominantes no Brasil. Em alinhamento com as políticas públicas contemporâneas, a obra escolar cristaliza o ideal moderno de difusão e ampliação do alcance social da arquitetura.

A análise comparativa dos exemplos referenciais de cada período sinaliza recorrências nas características arquitetônicas e nas formas de engendramento e organização do 
Figura 1: Diagrama de análise dos recreios cobertos. Fonte: Elaboração própria (NEDEL, 2016). espaço, que, muito embora incessantemente transformadas, evidenciam momentos de seu processo de constituição. Em tal análise, estudos gráficos sobre os desenhos técnicos das escolas foram efetuados para expor o caráter formativo do espaço, realçando a importância das circulações e dos espaços de sociabilização. Buscou-se, deste modo, fundamentar a noção de uma genealogia da arquitetura no âmbito dos edifícios escolares, ou seja, como processo contínuo de proposição, síntese e revisão de posturas (NEDEL, 2017). Tal noção exemplifica-se por meio de diagramas em que os recreios cobertos (Figura 1) ou outros aspectos dos projetos são demarcados, correlacionando obras representativas do Convênio Escolar, IPESP e FDE.

Para aprofundar a análise, selecionaram-se três escolas de distintos períodos da história das políticas públicas educacionais do estado de São Paulo, a título de estudos de caso, em que foram realizadas atividades de campo específicas: a EE Nossa Senhora da Penha (São Paulo, 1952), de Eduardo Corona, referente ao Convênio Escolar; a EE Conselheiro Crispiniano (Guarulhos, 1961), de Vilanova Artigas, construída na vigência do IPESP; a EE Professora Selma Maria Martins Cunha (Votorantim, 2006), de autoria do Grupo SP, referente ao período da FDE.

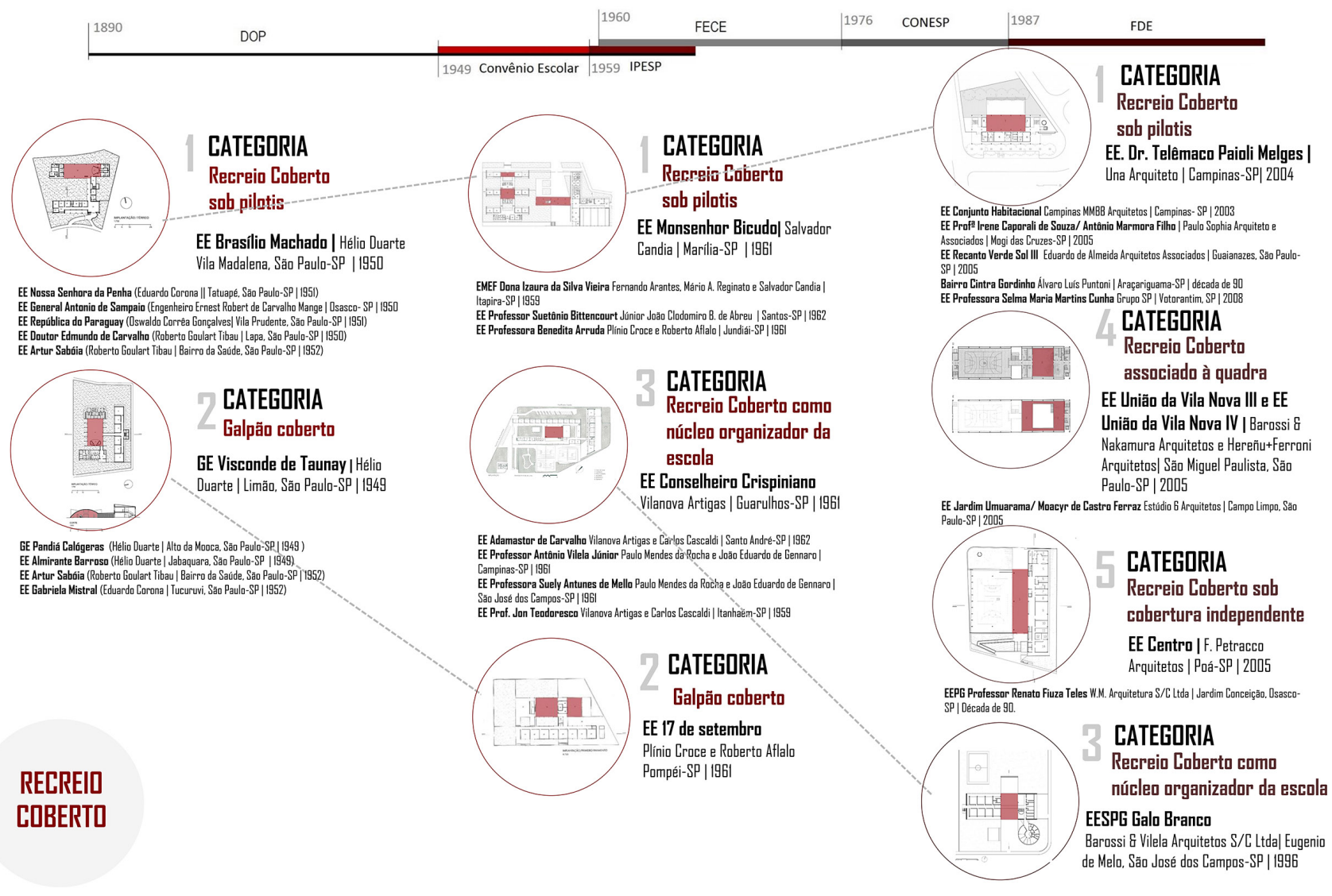




\section{EE NOSSA SENHORA EE CONSELHEIRO DA PENHA \\ EE PROFA. SELMA MARIA MARTINS CUNHA}

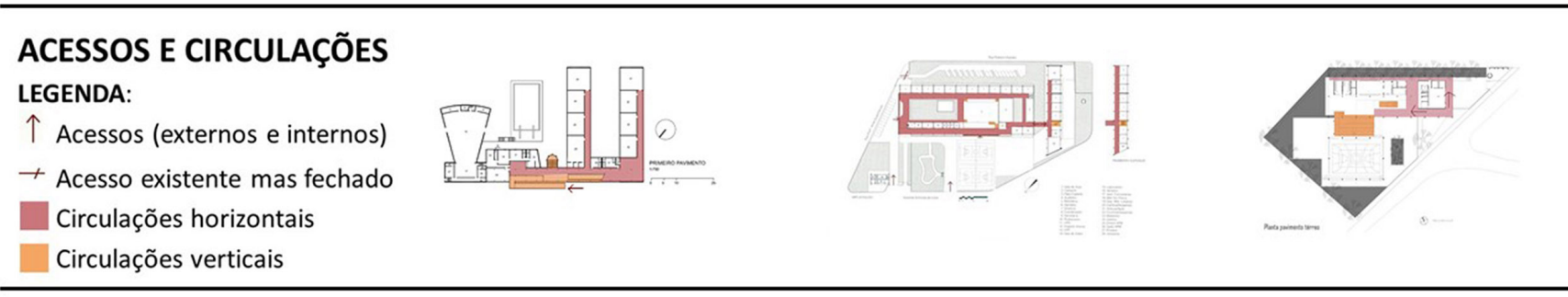

\section{ESPAÇOS DE RECREIO E ESTAR} LEGENDA:

Jardins internos

Recreio coberto

Jardim/recreio descoberto
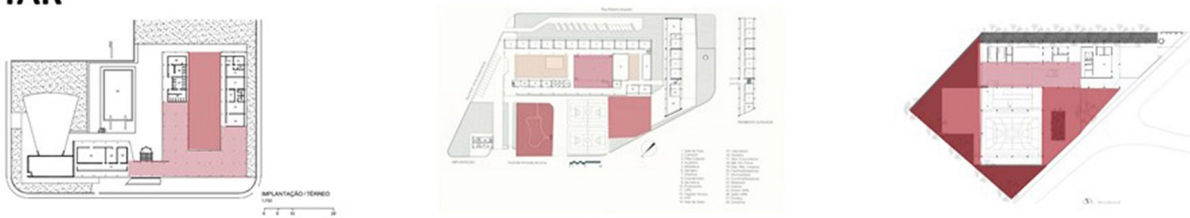

\section{ESPAÇOS E CONDIÇÕES}

\section{DE APROPRIAÇÃO}

\section{LEGENDA:}

Espaços programáticos

Espaços não programáticos ou de apropriação mais livre
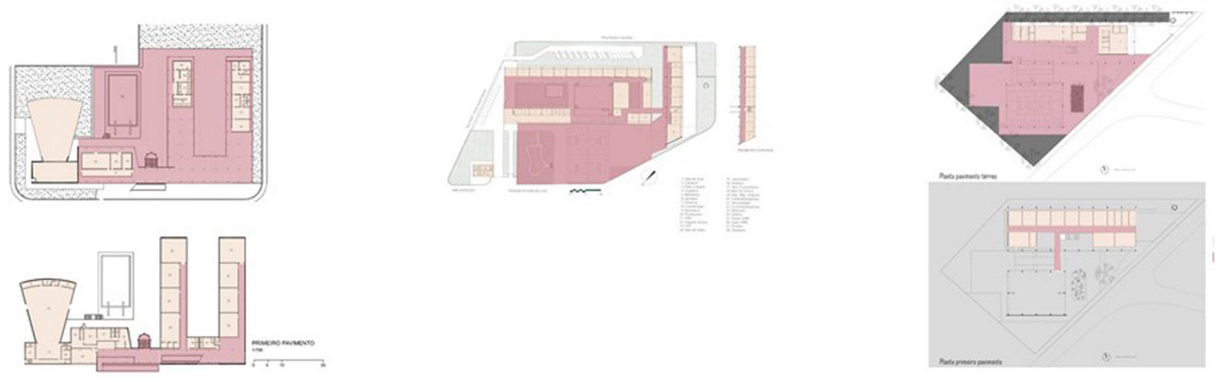

Figura 2: Estudos de caso: Acessos e circulações; Espaços de recreio e estar; Espaços e condições de apropriação. Fonte: Elaboração própria (NEDEL, 2016).

A visita a cada espaço envolveu o registro fotográfico das formas de apropriação espacial e das atividades de formação nos ambientes de ensino, recreio e sociabilização; a realização de entrevistas com os respectivos coordenadores pedagógicos sobre o cotidiano escolar, as demandas e inter-relações entre a arquitetura e as concepções pedagógicas, as características arquitetônicas originais e as apropriações concretas do espaço; bem como atividades com os alunos. No processo, a experiência espacial e a decorrente fruição em movimento do sujeito prolificam os níveis de leitura sobre os ambientes de ensino. Enquanto amostras de sua conformação social, permeadas por uma constelação de olhares, procurou-se capturar como os espaços são a sua vez vivenciados e apreendidos de modo a engendrar espacialidades outras, pela agregação de atributos distintos ao suporte construído. A somatória dessas perspectivas visuais ocultas, por ínfima que seja face ao conjunto da comunidade escolar, permitiu vislumbrar, ainda que parcialmente, o que entremeia a atividade pedagógica.

Por meio dos diagramas buscou-se analisar as potenciais relações entre o espaço construído e as apropriações pedagógicas e sociais, mediante a identificação dos espaços de percurso, dos espaços de recreio e estar e das configurações entre espaços programáticos e não programáticos dos três estudos de caso. Sobressai em tal leitura (Figura 2) a importância das circulações enquanto elemento articulador, ampliando potencialidades espaciais e sociais, tanto quanto as profícuas configurações que inter-relacionam o recreio coberto e os espaços externos, revelando os matizes de um espaço contínuo, aberto a apropriações mais livres, ainda que envolvam características bastante diversas. 
Figura 3: O corpo no espaço. Exploração fotográfica das condições de apropriação espacial na Escola Estadual Conselheiro Crispiniano. Fonte: Autoria própria (NEDEL, 2016).
A fotografia comparece, para além do registro do inerte, como meio de estudo da apropriação espacial, dos movimentos corporais que dinamizam a arquitetura, como exemplifica o estudo fotográfico da Escola Conselheiro Crispiniano. Nesta, os movimentos dos corpos entre os níveis da escola ressignificam o extenso banco, também local de sociabilização (Figura 3). A infância retratada no mural de Mário Gruber que compõe o pátio, figurando um espaço-tempo de liberdade e manifestação lúdica, é reiterada como tal nas vívidas apropriações livres dos que no pátio dessa escola as vivenciam.

Em fase subsequente, retornou-se à Conselheiro Crispiniano para realizar um conjunto de atividades específicas com os alunos, baseada em desenhos, conversas e entrevistas sobre suas percepções espaciais acerca do espaço arquitetônico, pedagógico e social. Na atividade de desenho com alunos do ensino fundamental, foi possível vislumbrar como certas questões arquitetônicas são percebidas por quem frequenta diariamente o ambiente escolar: o ritmo dos elementos estruturais, as diferenciações cromáticas dos elementos arquitetônicos, a relevância do mural para a ambiência do pátio, a permeabilidade visual ao exterior, as diferenças de nível entre salas de aulas e pátio, a integração do ambiente construído com os espaços verdes que o circundam ou interpenetram.

A atividade enriqueceu as leituras historiográficas consolidadas no campo acadêmico, por visibilizar percepções dos sujeitos que habitam cotidianamente o espaço. Os desenhos - com planos coloridos, ritmados, sobrepostos e sintomaticamente bidimensionais - reiteram o caráter pedagógico de um edifício caracterizado pela concisão estrutural, marcado por planos e pela diferenciação cromática de suas partes (Figura 4). O princípio neoplasticista caro à obra de Artigas, assim como seu diálogo com artistas concretos paulistas, ressoa no grau de abstração dos desenhos infantis, com uma expressão formal comum às obras de Alfredo Volpi, ensejando a associação concretista entre arte abstrata, cultura popular e princípios perceptivos intrínsecos à fisiologia da percepção (MEDEIROS, 2004).

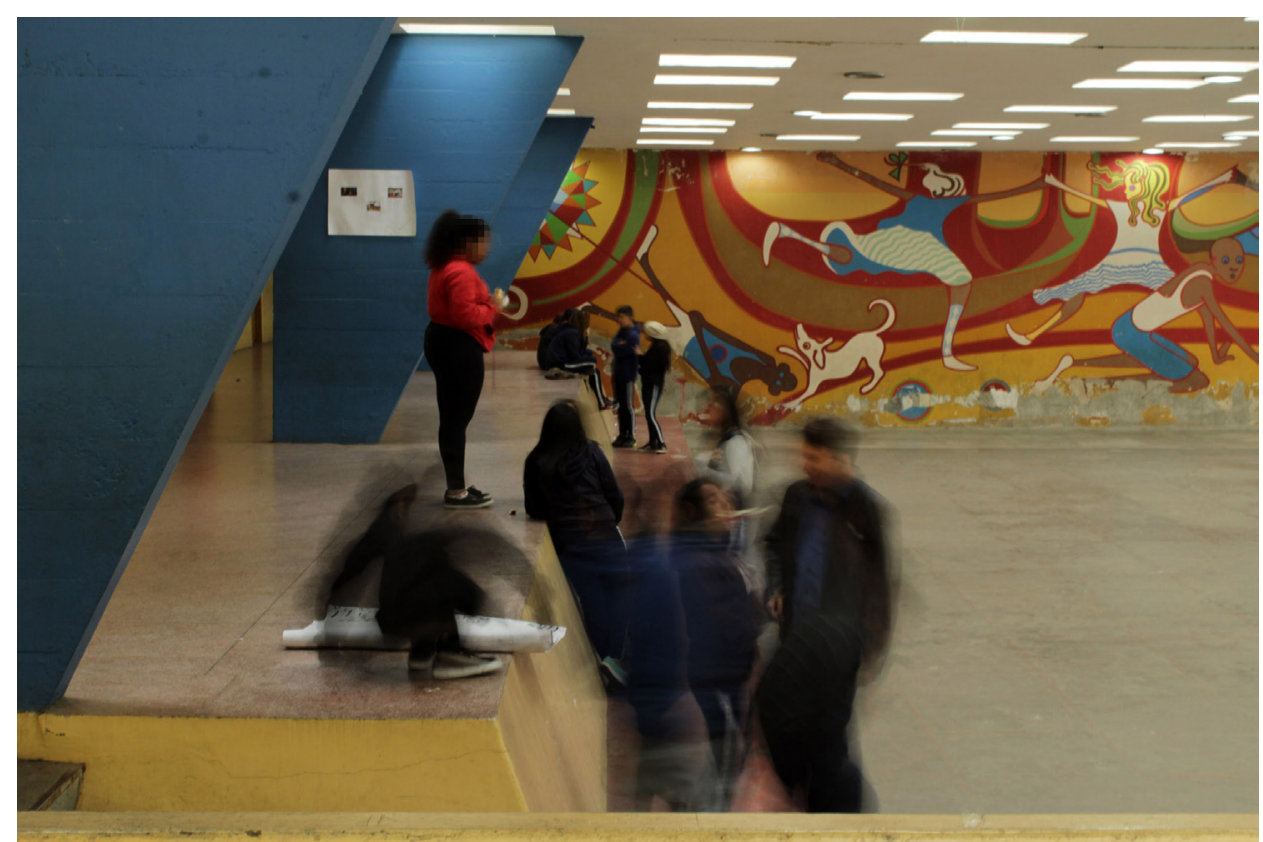


Figura 4: Desenho de aluno do sexto ano do ensino fundamental (2016). O olhar fixa a horizontalidade das faixas superpostas de pisos, banco e paredes, em contraponto ao ritmo dos pilares e portas das salas de aula. Fonte: Produção de um aluno a partir de atividade orientada pela pesquisadora (2016).

3 Trabalho realizado sob orientação da Profa. Dra. Maria Madalena Ferreira Pinto da Silva (FAUP) e do Prof. Dr. Givaldo Luiz Medeiros (IAUUSP). Para o resumo da pesquisa cf. Nedel, Silva, Medeiros (2017).

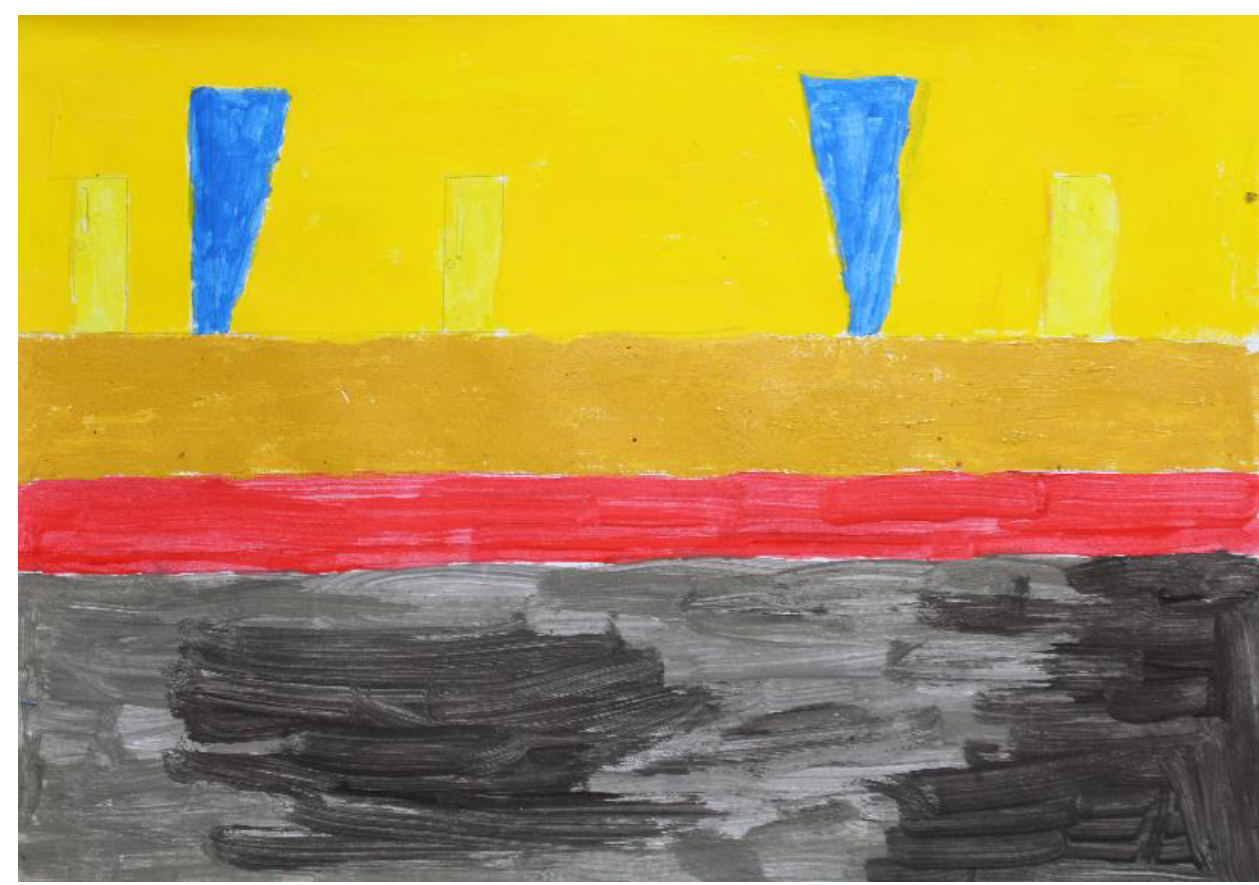

Com esse estudo dedicado à análise dos espaços escolares na produção paulista, procurou-se analisar o papel do edifício educacional no desenvolvimento de características que posteriormente constituíram a Escola Paulista de arquitetura, realçando a importância das escolas como laboratório de experimentação. A pesquisa apresentada a seguir enfocou a análise dos equipamentos escolares projetados pela Escola do Porto e efetua uma comparação interescalar entre projetos arquitetônicos, períodos da produção escolar, gerações de arquitetos e Escolas de arquitetura.

\section{Entre Escolas e escolas: espaços de formação na Escola do Porto e na Escola Paulista}

Enquanto extensão do trabalho anterior, o intercâmbio de pesquisa ${ }^{3}$ buscou aprofundar e compreender com maior refinamento crítico as especificidades e pontos de conexão entre os desenvolvimentos históricos da produção de edifícios escolares na Escola do Porto e o que foi analisado no âmbito da Escola Paulista, mantendo como argumento de fundo a compreensão da relação entre concepções espaciais e práticas pedagógicas. A abordagem cotejou obras e princípios arquitetônicos, com o intuito de averiguar ressonâncias, convergências, distinções e divergências.

Várias interpretações nuançam a expressão "Escola do Porto": a ideia de uma escola e de um ensino de arquitetura que "associa a pedagogia à prática profissional de um círculo de arquitetos (professores e ex-alunos) com ela relacionados" e para a qual contribui uma "ideia de legado" (MONIZ, 2011, p. 39); enquanto instituição vinculada a suas personalidades principais, assumida por Octávio Lixa Filgueiras como a Escola de Carlos Ramos (MONIZ, 2011); enquanto "criação de plataformas pedagógicas 
4 "Nem o arquiteto, nem o urbanista, nem o sociólogo, nem o economista, nem o filósofo ou o político podem tirar do nada, por decreto, novas formas e relações. Se é necessário ser exato, o arquiteto, não mais do que o sociólogo, não tem os poderes de um taumaturgo. Nem um, nem outro cria as relações sociais. Em certas condições favoráveis, auxiliam certas tendências a se formular (a tomar forma). Apenas a vida social (a práxis) na sua capacidade global possui tais poderes" (LEFEBVRE, 2001, p. 109). para o ensino da arquitetura" (ALVES COSTA, 2007, p. 219); enquanto construção de uma metodologia, segundo Siza: "É uma escola de tendência e com essa tendência, traduzida em programa e construção de uma metodologia, nos identificamos" (SIZA apud ALVES COSTA, 2007, p. 223).

Sobretudo a relevância conferida à pedagogia por Alves Costa estimulou a seleção de arquitetos alinhados com o ensino e a prática, a fim de analisar o processo, subjacente à Escola do Porto, de construção histórica de uma pedagogia e da prática profissional. Personagens e obras referentes a três gerações foram abordados: da $1^{\text {a }}$ Geração (anos 1920-30), Fernando Távora, Álvaro Siza e a dupla Alexandre Alves Costa e Sérgio

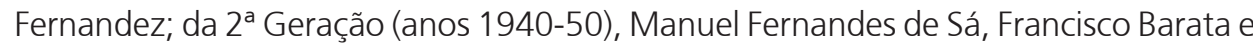
Eduardo Souto de Moura; da $3^{a}$ Geração (anos 1960-70), Nuno Brandão Costa, Nuno Valentim Lopes e a dupla Filipa de Castro Guerreiro e Tiago Correia. Complementar e concomitantemente, o estudo abarcou instituições de ensino relevantes sob o ponto de vista pedagógico ou pela relação obtida entre arquitetura e pedagogia, situadas no distrito ou no entorno do Porto. Além das duas seleções supracitados, fundamentada em revisão bibliográfica e iconográfica, o trabalho abrangeu visitas técnicas às obras e entrevistas com arquitetos responsáveis pelos projetos arquitetônicos e coordenadores pedagógicos dos referidos estabelecimentos educacionais.

As visitas constituem um método fundamental de análise das obras de arquitetura, visto que a inserção corporal e a fruição dinâmica do espaço proporcionam uma compreensão que atravessa a iconografia arquitetônica e os discursos pedagógicos e historiográficos, isto é, ampliam a apreensão fenomênica da obra com a efetiva vivência in loco (NEDEL, 2017). Afinal, como Henri Lefebvre (2001) bem conceitua, a despeito da influência da arquitetura no plano social, apenas a vida pode de fato determinar ou realizar relações sociais plenas. ${ }^{4}$

Os edifícios escolares e as Escolas de Arquitetura, temas de estudo, foram analisados e inter-relacionados para verificar os vínculos visíveis entre projetos arquitetônicos e concepções pedagógicas e entre as Escolas de arquitetura dos dois países. A pesquisa das escolas dos arquitetos do Porto reiterou as afinidades entre as gerações, como por exemplo, quanto ao intuito de construção com a paisagem, dialogando de forma a integrar-se a esta, como visível, por exemplo, na Escola de Hotelaria e Turismo de Eduardo Souto de Moura (Figuras 5); aos blocos dispersos e intercomunicados, conformando espaços livres nos interstícios (Figura 6); à fluidez de articulação de circulações e estares; à configuração de uma sucessão de escalas e transições espaciais distintas que se descortinam em meio ao percurso.

No que diz respeito às relações entre os edifícios escolares e as Escolas do Porto e Paulista, identificaram-se reciprocidades e dessemelhanças, perceptíveis na produção edificada de tais Escolas de modo geral, não apenas nos edifícios escolares. No entanto, constata-se não se tratar de características estritamente recorrentes e/ou observáveis em todas as obras de cada Escola, mas sim aspectos arquitetônicos presentes em um conjunto considerável delas. Como elementos de proximidade sobressaem as relações com o modernismo, embora com matizes distintos, referentes ao período de recepção nos respectivos países: em Portugal a influência da Centro-Europa (Walter Gropius, Robert Mallet-Stevens, Pieter Oud, William Dudok), e no Brasil a preponderância de 
Figura 5: Escola de Hotelaria e Turismo, Eduardo Souto de Moura (2 $2^{\mathrm{a}}$ geração). Fonte: Autoria própria (NEDEL, 2016).

Figura 6: Diagrama de análise dos recreios cobertos e dos espaços livres entre blocos edificados. Fonte: Elaboração própria (NEDEL, 2020).

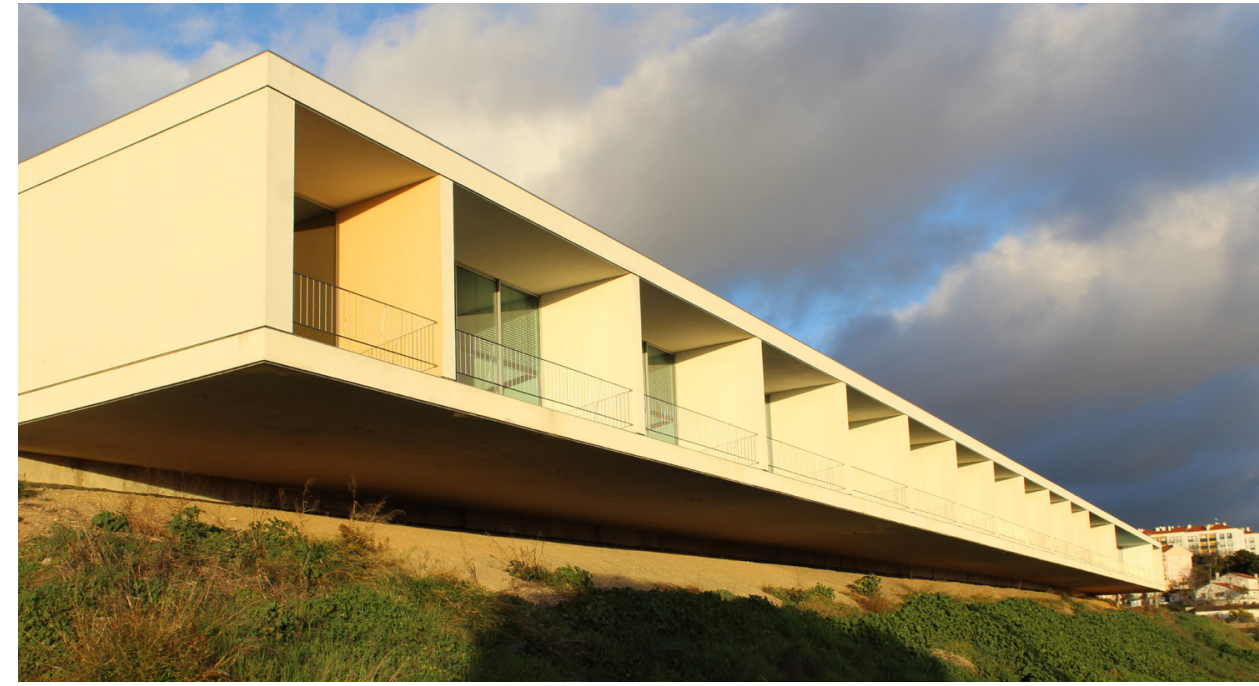


Le Corbusier. Em segundo lugar, o forte vínculo com a construção, seja pela questão da definição dos materiais e da riqueza de detalhamento construtivo ou devido à preocupação com princípios racionalistas e funcionalistas. Por fim, a importância do espaço interior, dos percursos, a questão da iluminação zenital, os aspectos de adequação ao entorno e as questões de ordem social.

Em relação às distinções entre as Escolas do Porto e Paulista, destacam-se as relações com o sítio, topografia e paisagem, com maior adaptação e valorização de suas qualidades, aproveitamento de visuais potenciais e apropriação das condições naturais nas obras da Escola do Porto; enquanto na Escola Paulista é frequente a alteração do terreno, o projeto constrói e reconstrói o sítio, em uma topografia construída. Também se diferenciam pelas relações com a dimensão humana: lá, uma arquitetura corporal, com forte ligação com a cultura humanista, o sentido de enraizamento e a experiência fenomênica; cá, associada à continuidade espacial e a sua amplitude. Sob o aspecto formal, na Escola do Porto observa-se maior fragmentação e dispersão dos blocos edificados, adaptados ao terreno e ao contexto urbano; já nos exemplares da Escola Paulista, com frequência se reúne todo o programa sob uma cobertura única, em prol do adensamento. Os distintos modos de assumir a história e a tradição revelam uma maior afinidade pela integração no contexto no âmbito português.

Consonâncias e dissonâncias repercutem nas atividades pedagógicas dos respectivos edifícios educacionais, sobretudo no que diz respeito às relações entre espaços internos e externos, percursos e estares, os questionamentos e distintas proposições programáticas, as relações almejadas entre o edifício, o entorno e a cidade. A pesquisa evidencia alguns pontos comuns: o caráter geracional que transcende a produção de ambas as Escolas; as políticas públicas que possibilitaram a difusão da arquitetura no estado de São Paulo; a polêmica em torno da expressão Escolas; a existência de um núcleo comum, ligado às duas Faculdades que formaram a ampla maioria dos que se reconhecem como pertencentes a tais Escolas, FAUUSP e FAUP; os espaços escolares enquanto ambiente de formação, não apenas instrução, o qual a arquitetura conforma, ainda que esta não tenha sido projetada, salvo exceções, de acordo com concepções pedagógicas claras e/ou específicas.

Para demarcar essas considerações, convém retornar à primeira pesquisa, que aborda aspectos de ambas as escolas, convergindo para a análise dos próprios recintos de formação, ambos emblemáticos do encontro entre as duas acepções de e(E)scola.

5Cf. Nedel e Medeiros (2014).

\section{escolas, Escolas: a elaboração do sítio na Escola Paulista e na Escola do Porto ${ }^{5}$}

A arquitetura pressupõe o entendimento do meio em que a obra está inserida, envolve aspectos urbanos, as condições topográficas, a inserção no lote, as relações com o sítio e com a paisagem, além da interação com outras edificações e com o entorno. Não obstante constituir uma solução técnica, inscreve-se no campo das manifestações sociais, culturais e sensíveis, exigindo, mais do que meros abrigos, lugares para a vida humana.

Cientes dos modos diversos de conceber e desenhar tais aspectos, a pesquisa elegeu a topografia, o sítio e a paisagem como fatores a pautar o estudo comparativo da 
Escola Paulista e da Escola do Porto, centrado em seis expoentes, a representar três gerações fundamentais para a proposição, consolidação e revisão de suas posturas. As obras de Vilanova Artigas, Paulo Mendes da Rocha e Marcos Acayaba, ao lado das de Fernando Távora, Álvaro Siza e Eduardo Souto de Moura, permitiram analisar o quanto a implantação, a construção topográfica e a relação com a paisagem conferem alguma especificidade a suas concepções arquitetônicas e, destarte, desenham as vertentes de cada Escola (NEDEL; MEDEIROS, 2014).

Embora os aspectos apontados não constituam um índice representativo na trajetória de todos os arquitetos considerados, distingue-se como um traço fundamental de certos projetos devido às particularidades do sítio (paisagem, entorno, condições geológicas, hidrológicas e/ou topográficas). Ou seja, indicam menos a temática que permeia a obra completa de determinado arquiteto do que as condições particulares com que enfrentam situação singulares. No entanto, nos projetos em que tais índices comparecem com destaque, nota-se uma obra propiciadora de experiências espaciais significativas, que proporciona ao usuário uma compreensão maior do espaço, ampliando e desdobrando as possibilidades de percurso, estares e perspectivas visuais. As questões relativas à topografia, paisagem, inserção no lote e interação com outras edificações forneceram parâmetros, por contraste ou similaridade, à valoração qualitativa das intervenções arquitetônicas e urbanísticas, permitindo reconhecer singularidades de cada Escola, os modos distintos de implicar arquitetura e elaboração topográfica.

A orgânica e sensível relação estabelecida entre a modelação do terreno e a exploração das afinidades com a paisagem, na Escola do Porto e até mesmo em certa tradição portuguesa, advém em grande parte das próprias características topográficas do país. Sobre um território em geral bastante irregular, as implantações buscam mitigar movimentos de terra, assumindo a topografia não como algo a ser suplantado pelo projeto, mas como parte constitutiva do mesmo. Na arquitetura do norte de Portugal, várias obras parecem então fundir-se ao solo, encravar-se tectonicamente para reafirmálo interna e externamente como espaço construído.

Ressalta-se que a relação com o sítio na Escola do Porto, em conjunção com o viés topográfico, busca afirmar a essência do lugar, a conformação original do terreno e a paisagem enquanto conotação histórica e social. O projeto arquitetônico inscreve-se no espaço concreto segundo uma abordagem fenomênica, afeita à experiência sensorial do espaço. Aos grandes movimentos de terra, sobrevêm as condições topográficas e paisagísticas originais, entendidas como preexistências. A implantação assume um viés orgânico, de índole pinturesca, enquanto dado apreensível através do deslocamento e da fruição em meio aos elementos lançados sobre o território e a paisagem. A fenomenologia do espaço desdobra-se na topografia e expressa a radicação no lugar, conferindo um sentido fundacional à obra.

Exemplifica esse caráter um projeto em especial, a FAUP de Álvaro Siza (Figuras 7 e 8), com um entendimento profundo do sítio, de sua espessura histórica e das relações visuais e espaciais suscitadas perante a paisagem. Trata-se de uma obra que é em si a estruturação de socalcos, o projeto dos níveis, dos percursos e do redesenho topográfico e paisagístico. Siza estuda a topografia, tira proveito dos muros de arrimo preexistentes, assim como restaura as instalações antigas da Quinta da Póvoa; implanta sua obra de acordo com os usos destinados aos 
terrenos e vias próximos ao local; desenha um sistema de acessos entre os diversos blocos propostos; reelabora uma ideia de pátio em chave moderna; replica elementos típicos do urbanismo de Portugal, como vias rampadas, largos e esquinas; enquadra a paisagem através dos eixos visuais e pelas janelas dispostas em ritmos inusitados; serve de marco visual para o entorno, enquadrando, suscitando caminhos e vistas possíveis; enfim, possibilita a vivência social, ao sabor dos percursos e dos lugares, pautando-se pelo ideário político e ideológico que constitui a Escola do Porto. Desse modo, a topografia distancia-se de ser uma condicionante exterior ao projeto, meros adoçamento ou embasamento da arquitetura, tornando-se uma parte constitutiva, que a define e reorienta-a, de fundamental importância para a gênese de uma causalidade interna ao projeto assim como para a interpretação e produção do sítio.

Se, na vertente portuguesa, a prática se mostra mais afeita à dispersão da ação sobre o terreno, na Escola Paulista prevalece a intervenção incisiva, porém concentrada, de inscrição contraposta ao sítio. Avessa à concepção fenomênica do espaço e ciosa da transformação pela via do engenho, sobressai uma abordagem que se supõe técnica, em que a topografia configura uma espécie de instância estruturadora do projeto, em atitude menos afetuosa acerca do sítio e, assim, mais radical. Em Artigas, o desdobramento em níveis e os espaços em si contribuem para que a concepção topográfica não se confunda com a expressão do lugar e constitua antes uma lógica operativa e formal, autônoma e renovadora, ligada à razão construtiva e ao partido adotado, em que a elaboração topográfica e territorial adquire contornos próprios, ao equiparar a remodelação do terreno ao plano referente da cobertura.

Vista sob o prisma da temática pesquisada, a FAU de Artigas (Figuras 9 e 10) é o exemplo modelar da Escola Paulista. Nesta obra, a construção, à primeira vista, parece apenas pairar sobre uma topografia pouco desafiadora. Como assinala Yves Bruand (1981), "tendo um terreno plano não gravado por compromissos, toda liberdade de ação Ihe foi dada e ele aproveitou-a amplamente" (BRUAND, 1981, p. 300). Entretanto, seu interior abriga um segundo terreno, solo criado por uma série de níveis e desníveis entre os pavimentos de lado a lado. Esses níveis se unem e se integram uns aos outros por meio de amplas rampas que promovem a continuidade espacial interna, ensejando uma espécie de promenade arquitetural. Aquém dos níveis elevados, o subsolo também se associa ao conjunto, primordial na formação de uma espécie de pirâmide invertida que adensa não apenas o terreno, mas tudo o que está sobre ele. Retomando Sophia Telles (1990) e sua argumentação a respeito do MuBE, também na FAU a operação topográfica condensa obra e terreno, redirecionando o viés topológico ao intento de interioridade e às concepções políticas do arquiteto, conforme corrobora Masao Kamita:

[...] um sentido telúrico a faz apegada à terra, às circunstâncias imediatas, à história material da vida; outro, transcendente, insiste no "direito de pensar utopicamente em face do mundo". [...] O projeto de Artigas adere a tal constatação, concebendo a arquitetura como construção de uma topografia habitável, um sistema de níveis intercalados e planos opacos, constituindo marcos artificiais que exigem um exercício constante de estruturação do espaço. A contenção e limpidez das formas são a contrapartida da liberação de fluxos, do moto perpétuo a deflagrar novos horizontes. (KAMITA, 2000, p. 181) 

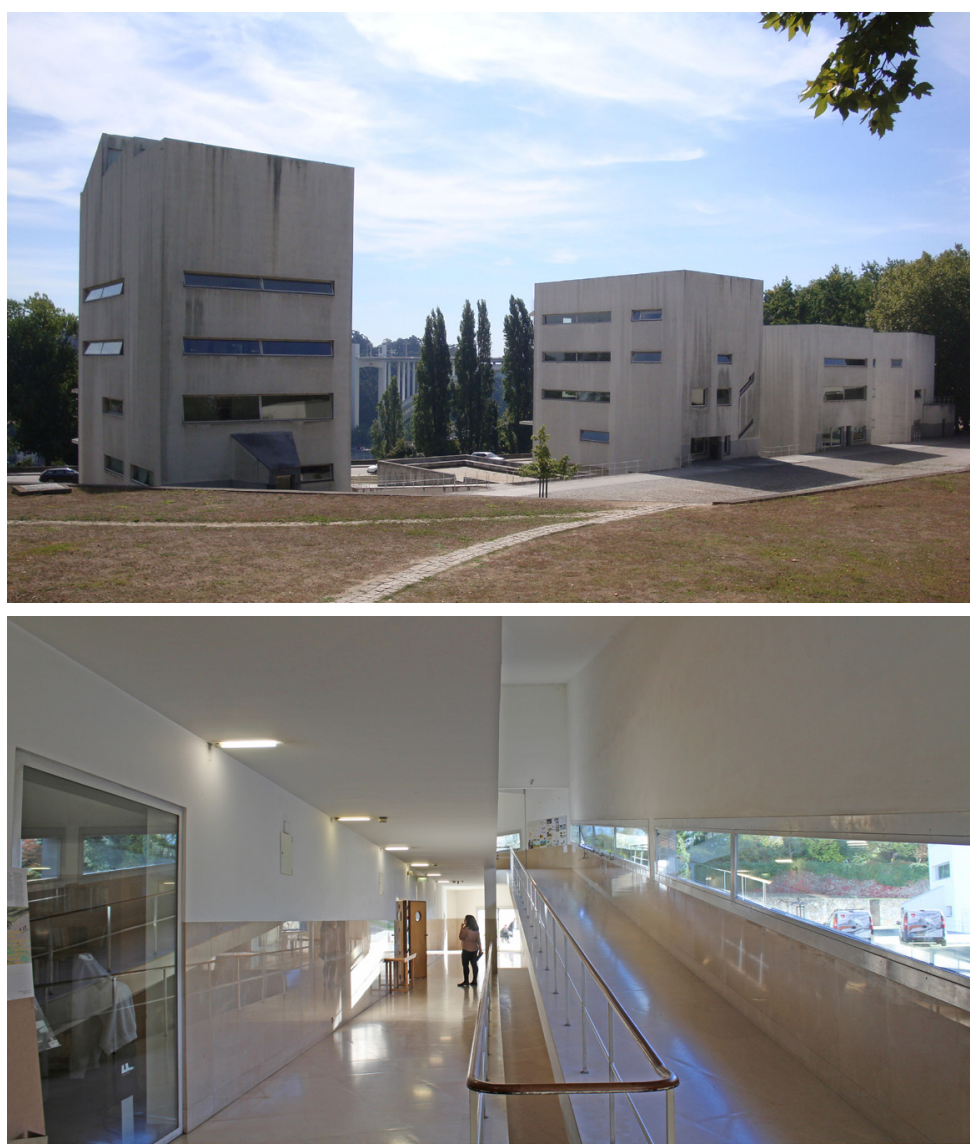

Figura 7: Blocos FAUP. Observar os blocos dispersos, porém articulados, a partir de uma praça aberta e por meio de galeria no nível térreo. Fonte: Autoria própria (MEDEIROS, 2013).

Figura 8: Espaço junto à rampa interna da FAUP. Observar os espaços mais contidos que vão se descortinando em meio ao percurso interno. Fonte: Autoria própria (NEDEL, 2016).

Figura 9: Pátio interno da FAU. Observar o grande vazio central no formato de pátio que congrega um forte sentido de interioridade ao bloco único. Fonte: Autoria própria (NEDEL, 2018).

Figura 10: Acesso à FAU. Observar o bloco único, maciço que, porém, encontra-se aberto ao exterior. Fonte: Autoria própria (NEDEL, 2018).
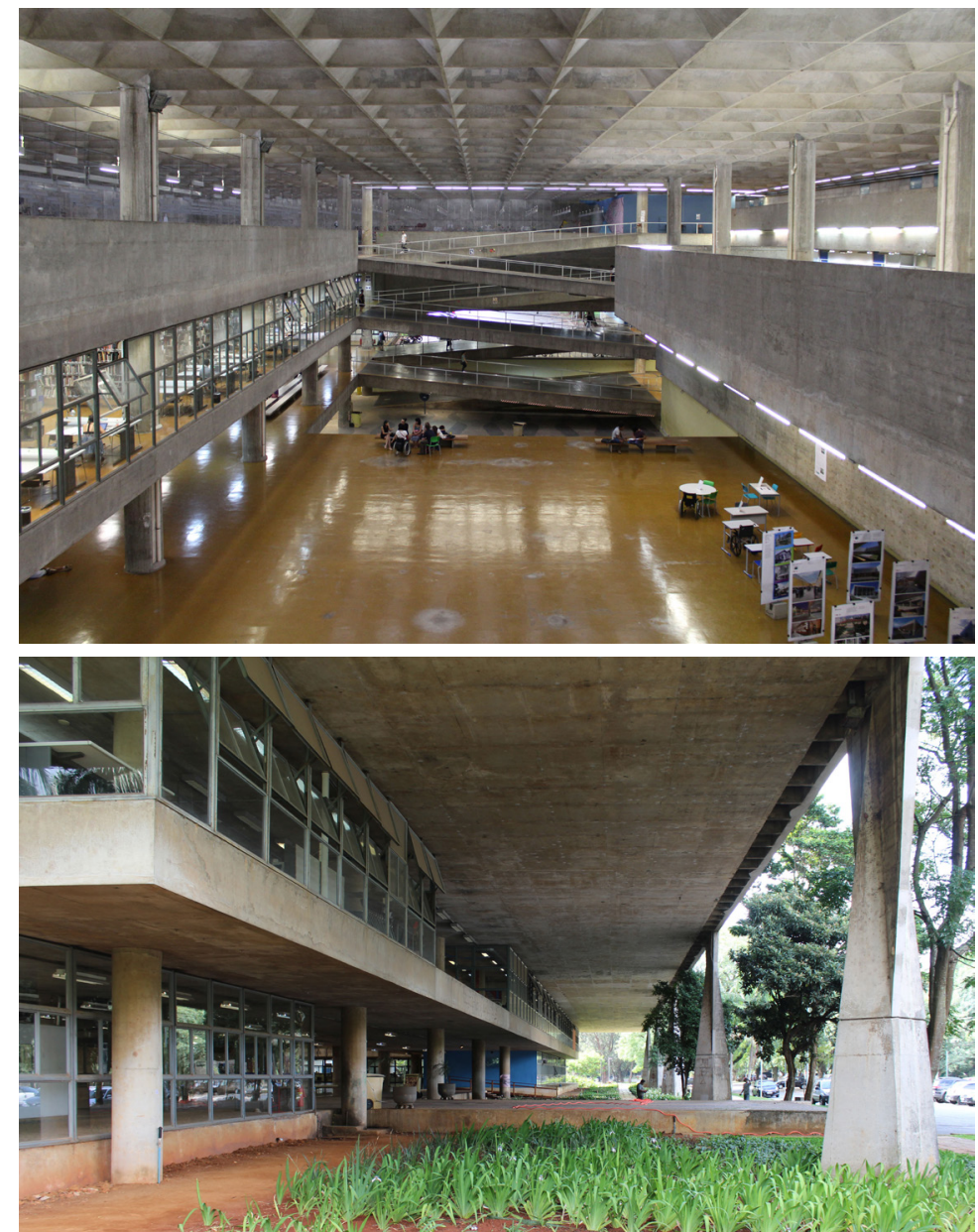
escolas, Escolas, estes edifícios, muito embora segundo desenhos distintos, sintetizam as experiências modelares de cada linhagem arquitetural. Edificações destinadas a instituições de ensino do próprio ofício, balizadas por ampla reflexão sedimentada nas trajetórias coletivas e individuais, que lhes conferem sentido em retrospectiva; obras de arquitetura paradigmáticas de modos de saber, fazer e conceber que expressam um legado cultural e o superam, infletindo o curso da história. Esta, como um rio, irriga em seu curso uma multiplicidade de vertentes, que essa pesquisa em parte percorreu ao acompanhar suas multifacetadas manifestações, em São Paulo e no Porto, entre educadores, alunos e arquitetos, sob o signo de uma mesma pátria arquitetural. Encontro de e(E)scolas.

\section{Referências bibliográficas}

ALVES COSTA, Alexandre. A viagem: Fernando Távora, a nossa Escola e o Desenho. Risco, São Carlos, v. 15, n. 2, p. 27-39, 2017. Disponível em: <http://www.revistas.usp.br/risco/ article/view/144446>. Acesso em: 10 set. 2019.

ALVES COSTA, Alexandre. Textos datados. Editorial do Departamento de Arquitectura da Faculdade de Ciências e Tecnologia da Universidade de Coimbra: Coimbra, 2007.

Legenda para um desenho de Nadir Afonso. In: TRIGUEIROS, Luiz (Ed.). Fernando Távora. Lisboa: Blau, 1993.

ARTIGAS, João Batista Vilanova. Duas residências. In: Acropole, n. 368, dez. 1969, p. 13-21. Disponível em: <acropole.fau.usp.br/edicao/368>. Acesso em: 01 set. 2020.

Os caminhos da arquitetura moderna (1952). In: ARTIGAS, Vilanova. Caminhos da arquitetura. São Paulo: Cosac Naify, 2004.

ARTIGAS, Rosa Camargo; THOMAZ, Dalva. Sobre brutalismo, mitos e bares. AU. Arquitetura e Urbanismo, São Paulo, n. 17, p. 61-63, abr.-maio 1988.

BRUAND, Yves. Arquitetura Contemporânea no Brasil. São Paulo: Editora Perspectiva, 1981.

DORIGATI, Remo. Um arquitecto, dois maestros e uma janela. Conversas. In: NUFRIO, Anna (Ed.). Eduardo Souto de Moura: conversas com estudantes. Barcelona: Gustavo Gili, 2008.

KAMITA, João Masao. Vilanova Artigas. São Paulo: Cosac Naify, 2000.

KATINSKY, Julio. Arquitetura paulista: uma perigosa montagem ideológica. AU. Arquitetura e Urbanismo, São Paulo, n. 17, p. 66-71, abr.-maio 1988.

LEFEBVRE, Henri. O direito à cidade. São Paulo: Centauro, 2001.

MEDEIROS, Givaldo Luiz. Artepaisagem: a partir de Waldemar Cordeiro. São Paulo: FAU-USP, 2004. Tese de Doutorado.

MONIZ, Gonçalo Esteves de Oliveira do Canto. O Ensino Moderno da Arquitectura. A Reforma de 57 e as Escolas de Belas-Artes em Portugal (1931-69). Dissertação de Doutoramento em Arquitectura. Departamento de Arquitectura. Faculdade de Ciências e Tecnologia da Universidade de Coimbra. Coimbra, 2011.

NEDEL, Miranda Zamberlan; MEDEIROS, Givaldo Luiz. Arquitetura, topografia e paisagem na Escola Paulista e na Escola do Porto. In: Anais do III ENANPARQ. Arquitetura, Cidade e Projeto: uma construção coletiva. São Paulo: Universidade Presbiteriana Mackenzie; Campinas: Pontifícia Universidade Católica de Campinas, 2014. Disponível em: <http://www.anparq. org.br/dvd-enanparq-3/htm/XFramesSumarioSC.htm>. Acesso em: 10 set. 2019.

Corpo, espaço e expressão gráfica no Ginásio de Guarulhos. In: GRAPHICA (International Conference on Graphics Engineering for Arts and Design), 2017, Araçatuba-SP. 
Anais GRAPHICA 2017. XII International Conference on Graphics Engineering for Arts and Design. 2017. Disponível em: <https://www.even3.com.br/anais/graphica2017/49747-corpo-espaco-e-expressao-grafica-no-ginasio-de-guarulhos/>. Acesso em: 10 set. 2019.

NEDEL, Miranda Zamberlan; MEDEIROS, Givaldo Luiz. Concepções espaciais e práticas pedagógicas: uma metodologia de investigação projetual aplicada a obras referenciais da arquitetura escolar paulista. In: VIII Seminário Internacional Projetar, 2018, Buenos Aires. Actas VIII Projetar 2017. Buenos Aires: Universidad de Buenos Aires, 2018. v. 1. p. 458-471. Disponível em: <http://projedata.grupoprojetar.ufrn.br/dspace/bitstream/123456789/2318/1/ Anais\%20do\%20Projetar2017.pdf>. Acesso em: 10 set. 2019.

NEDEL, Miranda Zamberlan; SILVA, Maria Madalena Ferreira Pinto da; MEDEIROS, Givaldo. Espaços de formação na Escola do Porto e na Escola Paulista: a experiência espacial nos ambientes de ensino. In: Revista Cadernos de Pesquisa da Escola da Cidade. São Paulo, v. 4, p. $173,2017$.

SIZA, Álvaro. apud ALVES COSTA, Alexandre. Textos datados. Editorial do Departamento de Arquitectura da Faculdade de Ciências e Tecnologia da Universidade de Coimbra: Coimbra, 2007.

TÁVORA, Fernando. O problema da casa portuguesa. Cadernos de Arquitectura n. ${ }^{\circ 1}$. Lisboa, 1947.

TELLES, Sophia. Museu da Escultura. AU. Arquitetura e Urbanismo, São Paulo, n. 32, p. 44-51, out.-nov. 1990.

TRIGUEIROS, Luiz (Ed.). Fernando Távora. Lisboa: Blau, 1993.

ZEIN, Ruth Verde. A obra do arquiteto. Projeto, São Paulo, n. 66, p. 79-91, ago. 1984.

Depoimento. AU. Arquitetura e Urbanismo, São Paulo, n. 17, p. 54-55, abr.-maio 1988. 